\title{
Does Social Trust Stimulate Regional Eco-Efficiency? Evidence From China
}

\author{
Youliang Yan ${ }^{1}$, Jixin Cheng ${ }^{1 *}$, Yunmin Wang ${ }^{1}$ and Yating $L^{2}{ }^{2}$ \\ ${ }^{1}$ School of Economics and Business Administration, Chongqing University, Chongqing, China, ${ }^{2}$ School of Transportation and \\ Logistics, Southwest Jiaotong University, Chengdu, China
}

OPEN ACCESS

Edited by:

Syed Jawad Hussain Shahzad, Montpellier Business School, France

Reviewed by: Yu Pang,

Macau University of Science and Technology, Macao, SAR China Abubakr Saeed, COMSATS University Islamabad, Pakistan

*Correspondence: Jixin Cheng chengjixin127@cqu.edu.cn

Specialty section: This article was submitted to Environmental Economics and Management, a section of the journal Frontiers in Environmental Science

Received: 25 April 2021 Accepted: 20 July 2021 Published: 29 July 2021

Citation: Yan Y, Cheng J, Wang Y and Li Y (2021) Does Social Trust Stimulate Regional Eco-Efficiency? Evidence

From China.

Front. Environ. Sci. 9:700139. doi: 10.3389/fenvs.2021.700139
Ecological efficiency is an important part of economic sustainable development. As the transitional economy with "weak institution" features, the informal institutions have a vital role in China's economic development. Using panel data from 2001 to 2016, this paper estimates eco-efficiency of China's 30 provinces based on Super-SBM DEA with global Malmquist index and investigates the governance role of a typical informal institution, namely social trust, in regional eco-efficiency. Empirical results show the following: 1) From 2001 to 2016, the accumulated changes of regional eco-efficiency are all greater than 1, indicating that all provinces in China are actively changing its development mode to improve eco-efficiency. 2) Social trust plays a significantly positive role in improving regional eco-efficiency. 3) Moreover, this effect is more pronounced in regions with poor legal development. 4) The mechanism tests further show that social trust can improve regional eco-efficiency through promoting regional green innovation and developing regional finance. Our findings shed light on the implications of informal institutions, and in particular on the value of social trust in realizing green economic development in emerging market.

Keywords: eco-efficiency, social trust, super-SBM DEA, global malmquist index, informal institution

\section{INTRODUCTION}

China has seen rapid growth and remarkable achievements in its economy during the past 40 years. However, the extensive mode of economic development inevitably leads to excessive resource exploitation, environmental pollution and ecological degradation (Xu and Yan, 2019). According to the China Ecological Environment Bulletin in 2018, 64.2\% of prefecture-level and above cities in China (which equals 217) have exceeded air quality standards, and a total of 186,000 administrative penalty cases related to environmental problems were handled nationwide, with a fine of up to 15.28 billion yuan. The Chinese central government clearly pointed out that China is now shifting its economic growth model from high-speed to high-quality. Apart from economic growth, governments at all levels should attach equal importance to environment protection and improvement of the eco-efficiency, while meeting the coordinated development of regions, to make local economy more sustainable.

In academic circles, a large number of scholars have conducted extensive researches on regional eco-efficiency and achieved many valuable results. Chen and Golley (2014) argue that the improvement of the eco-efficiency is a key signal to achieve a sustainable development model. The related literature mainly investigates the impact of environmental regulations (Hou et al., 2019a; Shuai and Fan, 2020), technological development (Zhang et al., 2018; Yang et al., 2020), urbanization process (Hou et al., 2019b; Zhou et al., 2020), and foreign direct investment (Lu and Pang, 2017; Wang, 2018) and on regional eco-efficiency. Different from western developed countries, China lacks 
an independent and efficient judicial system, and thus the existing laws, regulations, and rules are poorly enforced ${ }^{1}$. Given that the formal system do not work effectively, we may rely more on informal institutions (e.g., social trust, religious belief and local culture) to facilitate economic development (Allen et al., 2005; Yan et al., 2020) $)^{2}$. Formal institutions have the characteristics of compulsory and high constraint, which is often carried out by the government and directly imposed on market entities; while informal institutions shape individual or organizational decisionmaking preferences and behavior patterns through implicit norms and value orientation in a subtle and indirect way (Williamson, 2000). In order to achieve sustainable growth, besides formal system, it is necessary for us to fully understand what role the informal institutions play in improving regional eco-efficiency. Our paper intends to investigate the influence of social trust, a typical informal institution, on regional eco-efficiency.

According to the situation of 30 provinces in China, we first apply a Super Efficiency Slacks-based Measure (Super-SBM) data envelopment analysis (DEA) with global Malmquist index to analyze the changes in regional eco-efficiency from 2001 to 2016. In addition, we further empirically examine the influence of social trust on regional eco-efficiency. The results show that all regions in Chinese mainland are actively changing its development mode and the regional eco-efficiency has been improved during this period. Specifically, the improvement of eco-efficiency of Beijing and Tianjin is in the forefront of Chinese 30 provinces. Second, we find that social trust is significantly positively associated with regional eco-efficiency, suggesting a positive role of social trust in improving regional eco-efficiency. Moreover, the effect of social trust is more pronounced in regions with poor legal development. In China, legal development (formal institution) and social trust (informal institution) have a substitute governance impact on promoting economic green development. The mechanism tests further show that social trust can improve regional eco-efficiency by facilitating regional green innovation and promoting regional finance development. The results of the empirical regression are robust to alternative measures of social trust and remain valid after using two-stage least squares estimation to control for endogenous issues between social trust and regional eco-efficiency.

The paper makes the following contributions to the literature. First, this study extends the growing literature on the determinants of regional eco-efficiency in the transitional economy. The existing

${ }^{1}$ Here are some proofs: 1) The indexes of "ease of doing business", "Registering Property", "Getting Credit", and "Paying taxes", provided by The World Bank (2020) showed that China ranks 31,33,80,105, respectively, in 190 economies, worse than most other Asian economies such as Singapore, Korea, Malaysia, Thailand, and Japan. 2) In the study of Allen et al. (2005), China has an antidirector rights score of 3 , which is lower than $65 \%$ of sample countries (La Porta et al., 1998).

${ }^{2} \mathrm{~A}$ large number of literature highlights the positive role of informal institutions in explaining China's rapid economic growth (Allen et al., 2005; Xu et al., 2019). For example, Yan et al. (2020) show that, in the context of imperfect China's formal system, its local culture plays an important substitute role in protecting intellectual property rights and stimulating corporate R\&D activities, which can add impetus to economic development. Wu et al. (2014) find that regional trust has made a great contribution to the prosperity of trade credit and the optimization of capital allocation. literature on the influencing factors of regional eco-efficiency mainly focus on environmental regulations, technological development, urbanization process and foreign direct investment (Wang, 2018; Zhang et al., 2018; Hou et al., 2019a; Zhou et al., 2020). Combined with the important features of "weak institution" in the transitional economy, this paper reveals the positive governance role of social trust in regional eco-efficiency, which can add to the literature on the determinants of regional eco-efficiency. Second, this paper adds the literature on the economic consequences of social trust and contributes new knowledge to institutional theory. This theory emphasizes the importance of the informal system in promoting economic growth (North, 1990; Williamson, 2000; Allen et al., $2005)^{3}$. As a typical informal institution, social trust plays an important role in facilitating productive and cooperative actions, promoting business contracting and improving stock market (Coleman, 1990; Guiso et al., 2004; Ang et al., 2015; Jha, 2017; Li et al., 2017). In this study, we further empirically find that social trust can improve regional eco-efficiency to contribute in the green and sustainable development of the economy. Our findings shed light on the implications of informal institutions, and in particular on the value of social trust in Chinese business world. Third, this paper also presents a dynamic evolution of the regional ecoefficiency during 2001-2016 in China's 30 provinces by using the Super-SBM DEA approach with global Malmquist (GM) index, which can help the policy makers grasp the features of regional eco-efficiency and know the gains and losses in sustainable economic development in China. These results provide empirical evidence and useful reference for the policy-making of green governance in regional economic development.

This paper is organized as follows. In Literature Review and Theoretical Analysis, we review the relevant literature and develop our hypothesis. Research Methods and Data describes model specification and measures of variables in this study. Empirical Results introduces the estimated results of eco-efficiency in China's 30 provinces and tests the impact of social trust on regional eco-efficiency. In Conclusions and Policy Implications, we present the main conclusions and policy implications, limitation and future directions.

\section{LITERATURE REVIEW AND THEORETICAL ANALYSIS}

\section{Literature Review}

A rising of eco-efficiency is usually regarded as the transformation signal of economy towards a "sustainable" growth (Solow, 1957; Chen and Golley, 2014). Considering that Super-SBM DEA model can comprehensively reflect the green development level of DMUs and effectively rank them, therefore, it is widely used to evaluate regional eco-efficiency (Huang et al., 2014; Chen et al., 2019a; Yu

\footnotetext{
${ }^{3}$ Drawn of the analytical framework of institutional theory (Williamson, 2000), institutions are divided into four levels to affect economic activities: 1) informal system such as local culture, customs, traditions and social trust; 2) formal system such as laws, regulations, market rules; 3) governance mechanisms; 4) resource allocation and employment.
} 
et al., 2019). On this basis, to deepen the theoretical understanding of regional eco-efficiency, a growing number of scholars have further investigated the determinants of regional eco-efficiency and achieved considerable valuable achievements. Feng et al. (2017) calculate the green development performance index (GDPI) of 165 countries, and find that GDPI is positively correlated with living altitude, integrated oil price and energy structure, and negatively correlated with ecological carrying capacity. From the perspective of technological development, Yang et al. (2020) evaluate the $\mathrm{CO}_{2}$ emissions efficiency in manufacturing industry and emphasize that the technical progress has a promoting effect on industrial ecoefficiency. Zhang et al. (2018) also verify the positive influence of technological innovations on urban green development efficiency. In the process of urbanization, Hou et al. (2019b) show that the urbanization has an overall negative influence on the eco-efficiency of cultivated land. Zhou et al. (2020) similarly find that the population urbanization lag is also negatively associated with eco-efficiency. Moreover, given the importance of production factors, foreign direct investment can exert a positive impact on regional eco-efficiency (Lu and Pang, 2017; Wang, 2018). Besides, as the important formal institutions, environmental regulations have an obvious impact on the eco-efficiency of regional economy (Feng and Chen, 2018; Hou et al., 2019a; Shuai and Fan, 2020). Shuai and Fan (2020) argue that environmental regulations have an inverted U-shaped influence on the green efficiency of economic development (promoting and then suppressing). Similarly, Hou et al. (2019a) also show that environmental regulation has a "critical mass" effect on the governance of ecological efficiency. Once environmental regulation reaches a critical level, the regional ecoeconomic efficiency will decrease.

From the above literature analysis, we can get that focusing on ecological efficiency, existing scholars have investigates its determinants from multiple perspectives such as technological development, urbanization process, capital investment, environmental regulations. However, existing literature ignores the role of informal institutions (e.g., social trust) on regional ecological performance, which are essential social governance factors. Our study aims to fill this gap by testing the association between social trust and regional eco-efficiency.

\section{Impacts of Social Trust on Regional Eco-efficiency}

Institutional theory emphasizes that formal institutions (e.g., laws, government policies and regulations) and informal institutions (e.g., social trust, regional culture and value norms) are both important driving forces for economic growth (Williamson, 2000). Especially in the transition economy like China, given that its formal system is relative immature, the informal institutions may make greater contributions to social and economic development (Allen et al., 2005; Xu et al., 2019). As a typical informal institution, social trust describes an agent's subjective evaluation of the possibility of another agent to carry out certain actions, which presents the mutual trust among social members and the tendency of people to cooperate with each other (Coleman, 1990; Putnam et al., 1994). Regional trustiness will exert its influence in the form of value advocacy and implicit norms, which are imprinted on members of local society and reflected in individual behavior and corporate decision-making (Guiso et al., 2004, 2008; Li et al., 2017). In this sense, a growing body of literature has documented the governance role of social trust in curbing regional corruption (La Porta et al., 1997), improving investor protection (Cline and Williamson, 2016), stimulating R\&D activities (Ang et al., 2015), improving information disclosure quality and obtaining commercial credit (Garrett et al., 2014; Wu et al., 2014).

In our study, theoretically, social trust can influence regional eco-efficiency in the following ways: First, in such a relationshipcentered society as China, the reputation of social members is of great value for their survival and development in regional networks with high trust levels (Kong et al., 2020) ${ }^{4}$. In order to gain external trust and shape a good reputation, it is a good choice for market entities to actively assume environmental responsibility and contribute to regional sustainable development (Yan and $\mathrm{Xu}$, 2020). Thus, local enterprises will have more incentive to invest their energy and resources to optimize green production methods and improve ecological efficiency, so as to cater to external stakeholders and build their good corporate image. Second, in the process of realizing regional green development, social trust is also helpful to facilitate productive and cooperative actions, which can promote knowledge sharing and technological improvement about energy-saving and emission-reduction (Coleman, 1990; Guiso et al., 2004; Jha, 2017). Moreover, considering social trust can restrain the deprivation of intellectual property rights (Ang et al., 2015), enterprises in regions with high level trustworthiness also face less uncertainty risk of eco-innovation and thus be more enthusiastic about conducting R\&D activities to seek for ecological technology breakthroughs. Third, social trust can provide the implicit guarantee for borrowers and lenders, which will boost commercial credit and improve capital flow, thus optimizing the allocation of financial resources (Guiso et al., 2004; Wu et al., 2014). With the assistance of stronger financial support, the goals of green development can also be better implemented in each province, making it easier to improve regional eco-efficiency. Based on the above analysis, we thus propose the following hypothesis:

Hypothesis 1: Social trust will have a positive effect on the improvement of regional eco-efficiency.

\section{RESEARCH METHODS AND DATA Super-SBM Methodology and Global Malmquist Index}

We introduced a Super-SBM approach to avoid the deviation of radial models when evaluating the relative efficiency. Assume that the number of decision-making units (DUMs) is N and DUMs include three categories of variables: inputs, desirable outputs and undesirable outputs. We use three vectors, $x \in R^{m}, y \in R^{k_{1}}, c \in R^{k_{2}}$,

\footnotetext{
${ }^{4}$ The higher social trust means that members of regional network can make more use of their reputation advantages to obtain external support and reduce transaction costs, so as to create stronger corporate competitiveness.
} 
to denote these variables, and among which $m, k_{1}, k_{2}$ represent the numbers of each variable, respectively. Thus, the matrices are the following: $X=\left[x_{1}, \ldots, x_{N}\right] \in R^{m \times N}, \quad \mathrm{Y}=\left[y_{1}, \ldots, y_{N}\right] \in R^{k_{1} \times N}$, $C=\left[c_{1}, \ldots, c_{N}\right] \in R^{k_{2} \times N} . \lambda$ is the intensity vector. The production possibility set is as follows:

$$
P=\{(x, y, c) \mid x \geq X \lambda, y \leq Y \lambda, c \geq C \lambda, \lambda \geq 0\}
$$

Drawing on Huang et al. (2014), the SBM-efficient of $\mathrm{DMU}_{\mathrm{g}}$ is defined as follows:

$$
\begin{aligned}
& \theta^{*}=\min \frac{1+\frac{1}{m} \int_{i=1}^{m} \frac{s_{i}^{-}}{x_{i k}}}{1-\frac{1}{k_{1}+k_{2}}\left(\int_{r=1}^{k_{1}} \frac{s_{r}^{y}}{y_{r k}}+\int_{r=1}^{k_{2}} \frac{s_{r}^{c}}{c_{r k}}\right)} \\
& \left\{\begin{array}{c}
x_{k}-\int_{j=1, \neq k}^{n} \lambda_{j} x_{j}+s^{-} \geq 0 \\
s . t \quad y_{k}+\int_{j=1, \neq k}^{n} \lambda_{j} y_{j}+s^{y} \geq 0 \\
c_{k}-\int_{j=1, \neq k}^{n} \lambda_{j} c_{j}+s^{c} \geq 0 \\
1-\frac{1}{k_{1}+k_{2}}\left(\int_{r=1}^{k_{1}} \frac{s_{r}^{y}}{y_{r k}}+\int_{r=1}^{k_{2}} \frac{s_{r}^{c}}{c_{r k}}\right) \geq \varepsilon \\
\lambda, s^{-}, s^{y}, s^{c} \geq 0
\end{array}\right\}
\end{aligned}
$$

Where $\theta^{*}$ is the efficiency value of $\mathrm{DMU}_{\mathrm{g}} \cdot s^{-}, s^{y}, s^{c}$ are inputs slacks vectors, desirable outputs slacks vectors and undesirable outputs slacks vectors, respectively. The term $\varepsilon$ is non-Archimedean infinitely small. And production possibility is under the assumption of constant returns to scale (CRS).

To solve the model (2), we need to transform the fractional program into a liner-programming program by introducing the new variable of $\psi$ in such a way that lopenup $3 \psi\left[1-\frac{1}{k_{1}+k_{2}}\left(\int_{r=1}^{k_{1}} \frac{s_{r}^{y}}{y_{r k}}+\int_{r=1}^{k_{2}} \frac{s_{r}^{c}}{c_{r k}}\right)\right]=1$. Then, we obtain the following liner-programming program expression:

$$
\left.\begin{array}{c}
\theta^{*}=\min \psi+\frac{1}{m} \int_{i=1}^{m} \frac{S_{i}^{-}}{x_{i k}} \\
\psi x_{k}-\int_{j=1, \neq k}^{n} v_{j} x_{j}+S^{-} \geq 0 \\
-\psi y_{k}+\int_{j=1, \neq k}^{n} v_{j} y_{j}+S^{y} \geq 0 \\
s . t \quad \psi c_{k}-\int_{j=1, \neq k}^{n} \nu_{j} c_{j}+S^{c} \geq 0 \\
\psi-\frac{1}{k_{1}+k_{2}}\left(\int_{r=1}^{k_{1}} \frac{S_{r}^{y}}{y_{r k}}+\int_{r=1}^{k_{2}} \frac{S_{r}^{c}}{c_{r k}}\right)=1 \\
\nu, S^{-}, S^{y}, S^{c} \geq 0
\end{array}\right\}
$$

Where $v_{j}=\psi \lambda, S^{-}=\psi s^{-}, S^{y}=\psi s^{y}, S^{c}=\psi s^{c}$ in model (3), after solving this model, we can further get the optimal values of $\psi$ and all slacks.

In addition, to evaluate the changes of eco-efficiency of DMUs Malmquist (M) index. However, given that the linear programming infeasibility problem when using the $M$ index, following previous literature (Pastor and Lovell, 2005; Bing et al., 2010), we introduce a global Malmquist (GM) index in this study, and the global production possibility set is defined as:

$$
P^{G}=P^{1} \cup P^{2} \cup, \ldots, \cup P^{T}
$$

Where $T$ represents the sample interval; $P^{T}$ and $P^{G}$ are the contemporaneous production possibility and the global production possibility. Combined with the efficiency-based model (3), a GM index for evaluating the changes in regional eco-efficiency between period $t$ and $t+1$ can be written as:

$$
G M^{t, t+1}=\frac{\theta^{G}\left(x^{t+1}, y^{t+1}, c^{t+1}\right)}{\theta^{G}\left(x^{t}, y^{t}, c^{t}\right)}
$$

Where $\theta^{G}\left(x^{t+1}, y^{t+1}, c^{t+1}\right)$ and $\theta^{G}\left(x^{t}, y^{t}, c^{t}\right)$ denote the ecoefficiency of DMUs in the years of $t+1$ and $t$, respectively. Moreover, to calculate the accumulated changes of ecoefficiency, we set the GM index of the base period as 1, and then use the "cumulative multiplication" method to get the total changes of regional eco-efficiency (Feng et al., 2017; Feng and Wang, 2018).

\section{Regression Model}

In order to explore its impact on regional eco-efficiency from the perspective of social trust, we firstly establish a benchmark regression model, as shown in the following Eq. 6.

$$
\mathrm{AGM}=\alpha_{0}+\alpha_{1} \text { Trust }+\alpha_{2} \text { Controls }+ \text { Year }+\varepsilon_{i, t}
$$

Regional eco-efficiency is the dependent variable in our study, measured as AGM (accumulated changes of eco-efficiency). Trust is the explanatory variable, which is represents regional social trust. Controls is a set of control variables, including economic development $(G d p)$, industrial development level (Industry), energy structure (E-structure), regional population density (P-density), environmental regulations (Environment), opening up level (Open), infrastructure construction (Infrastructure), marketization level (Market) and economic policy uncertainty $(E p u)$. In addition, we also add year dummy variables to the model to control year fixed effect. $\varepsilon_{i, t}$ is random error.

\section{Measurements of Variables Dependent Variable: Regional Eco-Efficiency}

To calculate regional eco-efficiency $(A G M)$, following existing literature (Wang et al., 2017; Lin and Xu, 2018), the inputs of this paper contain labor $(L)$, capital $(K)$, energy consumption $(E)$, and the desirable and undesirable outputs are gross domestic product $(G D P)$ and $\mathrm{CO}_{2}$ emissions $(C)$, respectively. Specifically, $L$ is measured as the number of employees in each province; $K$ is the capital stock in each province, which is calculated by perpetual between two periods, Färe et al. (1994) firstly proposed 
TABLE 1 | Summary statistics of inputs and outputs.

\begin{tabular}{|c|c|c|c|c|c|c|}
\hline Index & Unit & Observations & Min & Max & Mean & S.D \\
\hline$L$ & $10^{4}$ persons & 480 & 279.00 & $6,726.39$ & $2,523.84$ & $1,674.76$ \\
\hline$E$ & $10^{4}$ tons & 480 & 364.52 & $34,483.99$ & $9,454.83$ & $6,914.07$ \\
\hline$K$ & 100 million $\mathrm{RMB}$ & 480 & 198.58 & $50,950.41$ & $7,608.15$ & $8,450.20$ \\
\hline Y & 100 million RMB & 480 & 289.66 & $52,177.81$ & $9,687.98$ & $9,373.24$ \\
\hline C & $10^{4}$ tons & 480 & 856.40 & $94,897.22$ & $25,525.26$ & $19,631.25$ \\
\hline
\end{tabular}

inventory method (Wang and Lin, 2018); E is measured as the standard coal consumption in each province; the desirable economic output is regional GDP; $C$ is the amount of $\mathrm{CO}_{2}$ emissions in each province (Yang et al., 2020). Table 1 reports the statistical description of the inputs and outputs for evaluating regional eco-efficiency.

\section{Explanatory Variable: Social Trust}

Social trust is the explanatory variable of our study. Following previous literature (Ke and Zhang, 2002; Wu et al., 2014; Ang et al., 2015; Li et al., 2017), we employ regional trust score to define Trust $_{1}$ to measure provincial-level trustworthiness. The data of trust score comes from a survey conducted by the Chinese Enterprise Survey System. The questionnaires of this survey were sent to over 15,000 entrepreneurs across China's 31 provinces, and their evaluation scores on the level of regional trustworthiness were investigated. The main question about trust is the following: "According to your experience, which five regions do you consider most trustworthy? List them in order." The first ranked province gets the highest five points, the second ranked province gets four points, and so on. The trust score of a province is calculated by the weighted average score of the trustworthiness rankings given by all entrepreneurs in the sample (Ke and Zhang, 2002). In addition, we further define another two variables, Trust $_{2}$ and Trust $_{3}$, as the alternative measures of social trust to conduct robustness checks ( $\mathrm{Li}$ et al., 2017). Trust t $_{2}$ is measured by per capita voluntary blood donation in each province. In general, blood donation reflects citizens' willingness to help others, cooperation, and altruism. The higher the blood donation rate, the more trust citizens have in the social system. Thus, it is a good choice to use provincial blood donation to capture regional trustworthiness (Wu et al., 2014; Ang et al., 2015). The data of voluntary blood donation were collected manually from the announcements issued by National Health Commission of China. Trust 3 is measured by the trustworthiness index in each province, which comes from the Annual Report on Urban Competitiveness in China. In this report, the trustworthiness index is calculated based on people's evaluation scores of the following questions: "What is the level of trustworthiness among citizens in your city?" The larger the index, the higher the regional social trust.

\section{Control Variables}

Following previous literature (Baker et al., 2016; Fu et al., 2018; Guo et al., 2020), we also define a set of control variables in the regression model. Economic development $(G d p)$ is measured as the natural logarithm of provincial GDP. Industrial development level (Industry) is measured as regional industrial output divided by local GDP. Energy structure (E-structure) is measured as coal consumption divided by regional energy consumption. Regional population density ( $P$-density) is measured as the population of per square kilometer. Environmental regulations (Environment) is measured as a comprehensive evaluation index of environmental regulations related to environmental protection status, measures and results (Fu et al., 2018). Opening up intensity (Open) is measured as the amount of regional total import and export divided by local GDP. Infrastructure construction (Infrastructure) is measured as the length of road transport line and railway transport line of per square kilometer. The marketization level (Market) is measured by the marketization index of each province compiled by the National Economic Research Institute. The uncertainty of economic policy (Epu) is measured as the average of all monthly economic policy uncertainty index in each year (Baker et al., 2016). In addition, we also add year dummy variables to the regression model to control year fixed effect. The descriptive statistics of the variables used in the regression model are reported in Table 2 .

\section{EMPIRICAL RESULTS}

\section{The Accumulated Changes of Eco-Efficiency in China}

Figure 1; Table 3 present the accumulated changes of regional eco-efficiency in different periods and in the whole sample period, respectively. As shown in Table 3, in the two periods of 2001-2004 and 2004-2008, the values of accumulated changes of eco-efficiency $(A G M)$ in each province is different, implying that the eco-efficiency of some provinces increased while other provinces declined. During the period from 2008 to 2012, the values of $A G M$ in China's 30 provinces are all greater than 1, indicating that the eco-efficiency of these provinces has improved during this period. During the period of 2012-2016, except for Anhui province $\left(A G M_{2012,2016}=0.9304\right)$, the $A G M$ values of other provinces are also greater than 1. Moreover, in four different time periods, the $A G M$ values of six provinces (Beijing, Tianjin, Hebei, Heilongjiang, Shanghai, Jiangsu, Guangdong) are greater than 1, suggesting that their ecoefficiency has improved in different sample periods.

Figure 1 shows that in the whole sample period from 2001 to 2016, all AGM values of 30 provinces in China are greater than 1, indicating the overall improvement of eco-efficiency in China. Among them, the accumulated increase of eco-efficiency of 
TABLE 2 | Descriptive statistics.

\begin{tabular}{|c|c|c|c|c|c|c|}
\hline Variables & Mean & Median & S.D & Min & Max & $\mathbf{N}$ \\
\hline Trust $_{1}$ & 0.3932 & 0.1515 & 0.5227 & 0.0410 & 2.1890 & 480 \\
\hline$A G M$ & 1.1192 & 1.0191 & 0.3386 & 0.7260 & 4.4645 & 480 \\
\hline$G d p$ & 8.7217 & 8.8346 & 1.0429 & 5.6687 & 10.8624 & 480 \\
\hline Industry & 0.4676 & 0.4824 & 0.0779 & 0.1926 & 0.6150 & 480 \\
\hline E-structure & 0.6609 & 0.6727 & 0.1268 & 0.1381 & 0.9253 & 480 \\
\hline P-density & 428.5737 & 279.4266 & 611.5988 & 7.2552 & $3,826.4984$ & 480 \\
\hline Environment & 0.6729 & 0.6845 & 0.1073 & 0.3019 & 1.4721 & 480 \\
\hline Open & 0.4188 & 0.1366 & 0.8265 & 0.0321 & 6.9566 & 480 \\
\hline Infrastructure & 0.1167 & 0.0993 & 0.0790 & 0.0071 & 0.3947 & 480 \\
\hline Market & 6.4174 & 6.2300 & 1.9616 & 2.3700 & 11.8000 & 480 \\
\hline Epu & 141.7740 & 123.9956 & 73.5790 & 64.9619 & 364.8328 & 480 \\
\hline
\end{tabular}

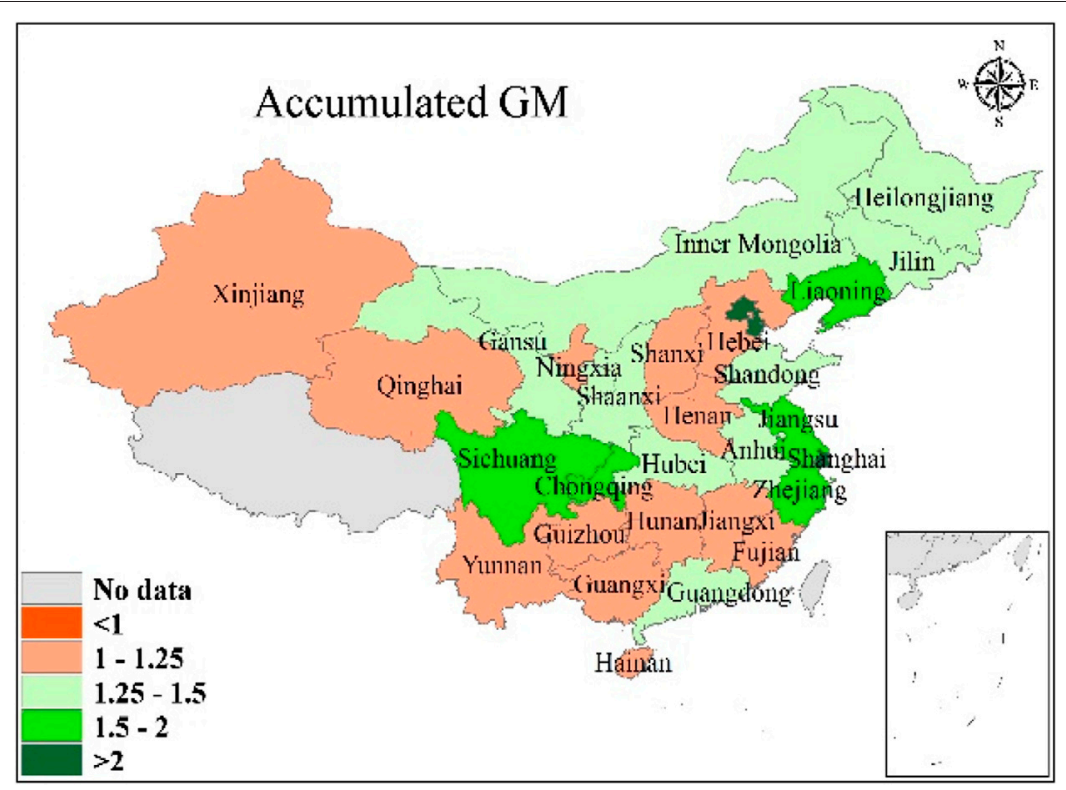

FIGURE 1| The accumulated changes of eco-efficiency in China's 30 provinces from 2001 to 2016.

TABLE 3 | The dynamic change of eco-efficiency of China's 30 provinces in different periods.

\begin{tabular}{|c|c|c|c|c|c|c|c|c|c|}
\hline \multirow{2}{*}{$\frac{\text { Interval }}{\text { Regions }}$} & \multicolumn{4}{|c|}{ AGM } & \multirow{2}{*}{$\begin{array}{l}\text { Interval } \\
\text { Regions }\end{array}$} & \multicolumn{4}{|c|}{ AGM } \\
\hline & 2001-2004 & 2004-2008 & 2008-2012 & 2012-2016 & & 2001-2004 & 2004-2008 & 2008-2012 & 2012-2016 \\
\hline Beijing & 1.0451 & 1.3977 & 1.4973 & 1.2866 & Henan & 0.9216 & 0.9295 & 1.1258 & 1.2013 \\
\hline Tianjin & 1.1255 & 1.1853 & 1.4685 & 2.1512 & Hubei & 0.8655 & 1.0205 & 1.1199 & 1.2682 \\
\hline Hebei & 0.9786 & 1.0694 & 1.1432 & 1.0717 & Hunan & 0.8874 & 0.8427 & 1.1889 & 1.1765 \\
\hline Shanxi & 0.9514 & 0.9439 & 1.2563 & 1.0527 & Guangdong & 1.0314 & 1.0780 & 1.0781 & 1.1365 \\
\hline Inner Mongolia & 1.0360 & 0.9846 & 1.3113 & 1.1720 & Guangxi & 0.8375 & 0.9813 & 1.0002 & 1.2192 \\
\hline Liaoning & 1.1643 & 0.7605 & 1.2341 & 1.7513 & Hainan & 0.8870 & 0.9868 & 1.0897 & 1.1465 \\
\hline Jilin & 0.9772 & 0.9150 & 1.1877 & 1.2186 & Chongqing & 0.9543 & 0.9172 & 1.4380 & 1.3528 \\
\hline Heilongjiang & 1.1109 & 1.0538 & 1.0581 & 1.0475 & Sichuan & 0.8641 & 1.0351 & 1.3364 & 1.3155 \\
\hline Shanghai & 1.0840 & 1.3703 & 1.5493 & 1.0015 & Guizhou & 0.9007 & 1.0365 & 1.1601 & 1.1020 \\
\hline Jiangsu & 1.0176 & 1.1139 & 1.2907 & 1.2264 & Yunnan & 1.2713 & 0.7071 & 1.1829 & 1.0628 \\
\hline Zhejiang & 0.9671 & 1.0682 & 1.2423 & 1.2437 & Shaanxi & 0.8707 & 0.9882 & 1.1910 & 1.2716 \\
\hline Anhui & 1.0281 & 1.1058 & 1.3921 & 0.9304 & Gansu & 0.9091 & 1.0515 & 1.1715 & 1.2206 \\
\hline Fujian & 1.0847 & 0.9832 & 1.0866 & 1.1163 & Qinghai & 0.9435 & 1.0050 & 1.2422 & 1.0154 \\
\hline Jiangxi & 0.9044 & 1.0209 & 1.2857 & 1.0567 & Ningxia & 0.9914 & 0.8764 & 1.0910 & 1.0765 \\
\hline Shandong & 0.9097 & 1.0577 & 1.2206 & 1.2854 & Xinjiang & 0.9698 & 1.0539 & 1.0083 & 1.0024 \\
\hline
\end{tabular}


TABLE 4 | The effect of social trust on regional eco-efficiency.

\begin{tabular}{|c|c|c|c|}
\hline \multirow[t]{2}{*}{ Variables } & \multicolumn{3}{|c|}{ AGM } \\
\hline & (1) & (2) & (3) \\
\hline Trust $_{1}$ & $0.2014^{\star \star \star}(8.34)$ & $0.1570^{\star \star \star}(4.51)$ & $0.1498^{\star \star \star}(4.53)$ \\
\hline$G d p$ & - & $0.0011(1.09)$ & $0.0445^{\star}(1.68)$ \\
\hline Industry & - & $-0.1022^{*}(-1.84)$ & $-0.0192(-0.31)$ \\
\hline E-structure & - & $-0.2062^{* \star \star}(-3.67)$ & $-0.2083^{\star \star \star}(-3.90)$ \\
\hline P-density & - & $-0.0886^{\star \star \star}(-4.58)$ & $-0.0419(-1.51)$ \\
\hline Environment & - & 0.0827 (1.34) & $-0.0383(-0.62)$ \\
\hline Open & - & $-0.0088(-0.75)$ & $-0.0171(-1.45)$ \\
\hline Infrastructure & - & $0.1428^{\star \star \star}(5.15)$ & $0.0624^{*}(1.66)$ \\
\hline Market & - & $0.0092(1.15)$ & $0.0340^{* \star \star}(3.27)$ \\
\hline Epu & - & $0.1184^{\star \star \star}(4.37)$ & $0.2281^{\star \star \star}(5.01)$ \\
\hline Constant & $0.0027(0.27)$ & $0.0516(0.22)$ & $-0.6500^{\star}(-1.95)$ \\
\hline Year effect & No & No & Yes \\
\hline$N$ & 480 & 480 & 480 \\
\hline $\operatorname{Adj} . R^{2}$ & 0.2108 & 0.4422 & 0.5303 \\
\hline
\end{tabular}

Beijing and Tianjin (AGMs 2001,2016 $>2$ ) is in the forefront of Chinese 30 provinces. In addition, the eco-efficiency of Liaoning, Jiangsu, Shanghai, Zhejiang, Chongqing and Sichuan also improved significantly during the period of 2001-2016 (AGMs $2001,2016>1.5$ ).

\section{The Effect of Social Trust on Regional Eco-Efficiency}

In Table 4, we present the main results of the regression on the impact of social trust on regional eco-efficiency. As shown in Column (1)-(3), where control variables and year-fixed effect are gradually included in regression model, we find that all coefficients on Trust $_{1}$ are positive and statistically significant at $1 \%$ level $(0.2014$ with $t=8.34,0.1570$ with $t=4.51,0.1495$ with $t=$ 4.53), which suggests social trust has a positive impact on improving regional eco-efficiency. In China, regions with high level of social trust are more likely to provide strong financial support and carry out cooperative and productive activities on ecological innovation, thus promoting the improvement of their eco-efficiency.

\section{The Moderating Effect of Legal Development}

Institutional theory argues that when the formal system is not perfect, the informal institutions play an important substitute governance role in social and economic development (Williamson, 2000; Allen et al., 2005). China is a vast country with the features of unbalanced development in different provinces. In regions with higher level of legal development, a more perfect institutional system can regulate the competitive behaviors of market entities in an orderly manner, effectively curb the non-conforming business behaviors such as environmental pollution and excessive carbon emissions, which will provide institutional guarantee for the improvement of regional ecological efficiency. When the legal system is immature, the substitute role of informal institutions in ecological governance will be further highlighted. In this section, we aim to test the moderating role of legal development in the relationship between social trust and regional eco-efficiency.

We first define a variable, law, to measure legal development in each province. Law is defined by the regional legal civilization index, which is compiled by the report on China Justice Index. Then, we add the legal development (Law) and the interaction item ( Trust $_{1} \times$ Law) into model (6) to test the moderating effect of legal development. As shown in Table 5, in Column (1)-(3), the coefficients on Trust $_{1}$ and Law are all significantly positive, indicating the positive effect of social trust and legal development on regional eco-efficiency. More importantly, the

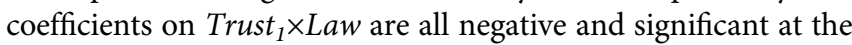
$1 \%$ level, suggesting that the positive role of social trust in improving eco-efficiency is more pronounced in regions with poor legal development. Our results imply that the legal development (formal institution) and social trust (informal institution) have a substitute governance impact on improving regional eco-efficiency.

\section{Robustness Checks}

\section{Endogeneity Correction}

When testing the association between social trust and regional eco-efficiency, the results may be influenced by potential endogenous problems, which are caused by some unobservable characteristics. To enhance the robustness of our evidence, we conduct a two-stage least squares (2SLS) estimation and reestimate the main results.

A growing number of literature shows that the regional culture has an important effect on individual cognition, social values and ethical behavior (Du, 2015; Baxamusa and Jalal, 2016). In the Chinese context, the Confucianism is the most extensive and farreaching cultural symbol, and its emphasis on faithfulness plays a prominent role in shaping Chinese social norms (Xu et al., 2019). China's Confucian culture will contribute to the promotion of regional social trust (Kung and Ma, 2014; Du, 2015). Following

TABLE 5 | The moderating effect of legal development.

\begin{tabular}{|c|c|c|c|}
\hline \multirow[t]{2}{*}{ Variables } & \multicolumn{3}{|c|}{ AGM } \\
\hline & (1) & (2) & (3) \\
\hline Trust $_{1}$ & $0.2014^{\star \star \star}(8.34)$ & $0.1634^{\star \star \star}(4.61)$ & $0.1537^{\star \star \star}(4.57)$ \\
\hline Trust $_{1} \times$ Law & $-0.2296^{\star \star \star}(-4.79)$ & $-0.1941^{\star \star \star}(-4.81)$ & $-0.2451^{\star \star \star}(-6.55)$ \\
\hline Law & $0.1386^{\star \star \star}(4.10)$ & $0.1491^{\star \star \star}(4.66)$ & $0.1594^{\star \star \star}(5.84)$ \\
\hline$G d p$ & - & $0.0070(0.57)$ & $0.0393^{* *}(2.43)$ \\
\hline Industry & - & $-0.1217^{* \star}(-2.14)$ & $-0.0009(-0.01)$ \\
\hline E-structure & - & $-0.2005^{\star \star \star}(-3.61)$ & $-0.1911^{\star \star \star}(-3.65)$ \\
\hline P-density & - & $-0.0886^{\star \star \star}(-4.55)$ & $-0.0365(-1.31)$ \\
\hline Environment & - & 0.0803 (1.30) & $-0.0534(-0.86)$ \\
\hline Open & - & $0.0002(0.01)$ & $0.0045(0.34)$ \\
\hline Infrastructure & - & $0.1225^{\star \star \star}(4.37)$ & $0.0267(0.68)$ \\
\hline Market & - & $0.0115(1.43)$ & $0.0406^{\star \star \star}(3.77)$ \\
\hline Epu & - & $0.1216^{\star \star \star}(4.49)$ & $0.2368^{\star \star \star}(5.17)$ \\
\hline Constant & $-0.0074(-0.70)$ & $-0.0861(-0.35)$ & $-0.8943^{\star \star}(-2.61)$ \\
\hline Year effect & No & No & Yes \\
\hline$N$ & 480 & 480 & 480 \\
\hline $\operatorname{Adj} . R^{2}$ & 0.2326 & 0.4593 & 0.5531 \\
\hline
\end{tabular}


TABLE 6 | Robustness checks of two-stage least squares (2SLS).

\begin{tabular}{|c|c|c|}
\hline \multirow[t]{3}{*}{ Variables } & First stage & Second stage \\
\hline & Trust $_{1}$ & $A G M$ \\
\hline & (1) & (2) \\
\hline Trust $_{1}$ & - & $0.1582^{\star \star \star}(3.87)$ \\
\hline Confucian & $0.0220^{\star \star \star}(16.22)$ & - \\
\hline Controls & Yes & Yes \\
\hline Constant & $-2.3854^{\star \star \star}(-5.86)$ & $0.4841(0.99)$ \\
\hline Year effect & Yes & Yes \\
\hline$N$ & 480 & 480 \\
\hline $\operatorname{Adj} . R^{2}$ & 0.6193 & 0.5302 \\
\hline
\end{tabular}

Note: ${ }^{* * *}, "$, and * indicate significance at the level of 1, 5 and 10\%, respectively.

previous literature (Du, 2015; Chen et al., 2019b; Xu et al., 2019), we first manually collect the number of Confucian academies established in each province recorded in historical documents. Then, using the natural logarithm of the number of Confucian academies, we define a new variable, Confucian, to measure the influence Confucian culture in each province. Considering that the historical Confucian academies cannot directly influence the current regional eco-efficiency, we thus choose Confucian as instrumental variables to run two-stage least squares estimation.

The results are presented in Table 6. In the first stage, the coefficient on Confucian is significantly positive, suggesting the positive role of Confucian culture in shaping social trust. After using the two-stage least squares estimation to alleviate endogeneity, the coefficient on Trust $_{1}$ is still positive and statistically significant $(0.1582$ with $t=3.87)$, providing strong support for the positive impact of social trust on improving regional eco-efficiency.

\section{Alternative Measures of Social Trust}

In this section, to enhance the robustness of our findings, we employ alternative measures of social trust to conduct robustness checks. Following previous literature (Ang et al., 2015; Li et al., 2017), we choose per capita voluntary blood donation $\left(\right.$ Trust $_{2}$ ) and the provincial-level trustworthiness index $\left(\right.$ Trust $\left._{3}\right)$ to reestimate the relationship between social trust and regional ecoefficiency. Table 7 reports the regression results. The coefficients on Trust $_{2}$ and Trust $_{3}$ are positive and significant at $1 \%$ level ( 0.0736 with $t=5.58,0.0196$ with $t=7.06$ ), implying the positive impact of social trust on improving regional efficiency, which is consistent with the previous findings.

\section{Mechanism Tests: The Role of Regional Green Innovation and Finance Development}

In this section, we further analyze the mechanism of social trust affecting regional eco-efficiency. In the process of sustainable development of regional economy, innovation undoubtedly plays an indispensable role (Zhang et al., 2018; De Jesus et al., 2019; Wang and Yang, 2019). As an important driving force for development, innovation can ameliorate enterprise's production technology, reduce unnecessary waste of resources and undesirable emissions of pollutants, thus improving regional
TABLE 7 | Robustness checks using alternative measures of social trust.

\begin{tabular}{|c|c|c|}
\hline \multirow[t]{2}{*}{ Variables } & $A G M$ & $A G M$ \\
\hline & (1) & (2) \\
\hline Trust $_{2}$ & $0.0736^{\star \star \star}(5.85)$ & - \\
\hline Trust $_{3}$ & - & $0.0196^{\star \star \star}(7.06)$ \\
\hline Controls & Yes & Yes \\
\hline Constant & $-1.6414^{\star \star \star}(-4.84)$ & $-2.6370^{\star \star \star}(-5.06)$ \\
\hline Year effect & Yes & Yes \\
\hline$N$ & 480 & 480 \\
\hline $\operatorname{Adj} . R^{2}$ & 0.5346 & 0.5638 \\
\hline
\end{tabular}

energy efficiency. A high level of regional social trust can help companies to cooperate in R\&D and knowledge sharing, which conduce to green technology breakthrough and innovation (Coleman, 1990; Guiso et al., 2004; Ang et al., 2015; Jha, 2017). Therefore, we choose regional green innovation as the mediating variable to explore the mechanism of social trust for regional eco-efficiency. In addition, the existing literature also shows that the regional financial development will contribute to liberalizing capital and vitalizing business of enterprises (Almeida and Campello, 2007; Hsu et al., 2014; Ang et al., 2015; Cull et al., 2015). In regions with more developed finance, enterprises will be more easily to obtain financial support to implement green development goals and improve their ecological efficiency. As an important informal institution, social trust can function as a type of implicit guarantee between borrowers and lenders, thus improving the flow of capital, which will increase the effective allocation of financial resources and promote the development of local financial development (Guiso et al., 2004). Therefore, we also choose regional finance development as the mediating variable to explore the mechanism of social trust for regional eco-efficiency.

Following the method of Baron and Kenny (1986), we examine the influence channel with a mediation model. In particular, we define two mediating variables of Green_innov and Finance to measured regional green innovation and finance development, respectively. 1) Green_innov is measured as the natural logarithm the amount of provincial green patents, which comes from China National Intellectual Property Administration ${ }^{5}$. 2) Finance is measured as total loans of regional financial institutions divided by local GDP. We first examine the influence of social trust on regional green innovation and finance development. Then, we add independent variable $\left(\right.$ Trust $\left._{1}\right)$ and mediating variables (Green_innov, Finance) into the same regression model to test their impact on regional eco-efficiency.

The regression results are reported in Table 8. In Column (1) and (2), the coefficients on Trust $_{1}$ is positive and significant at $1 \%$ level ( 0.6967 with $t=3.87,0.2943$ with $t=9.89)$, implying that social trust has a positive impact on improving regional green innovation and promoting regional finance development. After we add the independent variable (Trust ${ }_{1}$ ) and mediating variables

${ }^{5}$ We identify whether a patent is a green patent according to the "IPC Green
Inventory" issued by World Intellectual Property Organization (WIPO) in 2010. 
TABLE 8 | Mechanism tests: the role of regional green innovation and finance development.

\begin{tabular}{|c|c|c|c|}
\hline \multirow[t]{2}{*}{ Variables } & Green_innov & Finance & AGM \\
\hline & (1) & (2) & (3) \\
\hline Trust $_{1}$ & $0.6967^{\star \star \star}(3.87)$ & $0.2943^{\star \star \star}(9.89)$ & $0.0862^{\star \star \star}(2.60)$ \\
\hline Green_innov & - & - & $0.0231^{\star \star \star}(2.78)$ \\
\hline Finance & - & - & $0.1616^{\star \star \star}(4.27)$ \\
\hline Controls & Yes & Yes & Yes \\
\hline Constant & $-5.9838^{\star \star \star}(-3.14)$ & $-0.0225(-0.07)$ & $-0.5080(-1.42)$ \\
\hline Year effect & Yes & Yes & Yes \\
\hline$N$ & 480 & 480 & 480 \\
\hline Adj. $R^{2}$ & 0.4572 & 0.4762 & 0.5564 \\
\hline
\end{tabular}

Note: ${ }^{* * *}, "$, and * indicate significance at the level of 1, 5 and 10\%, respectively.

(Green_innov, Finance) into the same model, as shown in Column (3), the coefficients on Green_innov and Finance are both positive and significant at $1 \%$ level ( 0.0231 with $t=2.78$, 0.1616 with $t=4.27)$, indicating that regional green innovation and finance development have a positive influence on improve regional eco-efficiency. In addition, we also find that the coefficient of Trust $_{1}$ is still significantly positive. Compared with the coefficient in Column (3) of Table 4, the magnitude and significance level of Trust $_{1}$ have decreased. These results suggest that regional green innovation and finance development play a mediating role between social trust and regional ecoefficiency. That is to say, social trust can improve regional eco-efficiency through promoting regional green innovation and finance development.

\section{CONCLUSION AND POLICY IMPLICATIONS}

\section{Conclusion}

As an important emerging market, China has experienced remarkable achievements in its economy over the past decades. However, its rapid economic development is inevitably accompanied by air pollution, greenhouse gas emissions and other environmental problems, which arouses concern from all walks of life. The realization of green and sustainable development has become a basic goal of China's economic transformation. In the Chinese market with the characteristics of "weak institution" (Allen et al., 2005), given that the formal system is relatively immature, understanding whether and how social trust stimulate regional eco-efficiency would add value to both the theory and the practice of economic sustainable development. This paper aims to investigate the effect of social trust on regional eco-efficiency in China.

The empirical results show that: 1) from 2001 to 2016, the accumulated changes of eco-efficiency of China's 30 provinces are all greater than 1, indicating that all regions in Chinese mainland are actively changing its development mode and the regional ecoefficiency has improved during this period. In addition, we find that the accumulated increase of eco-efficiency of Beijing and Tianjin is in the forefront of Chinese 30 provinces, and their AGM values are all greater than 2. 2) We find that social trust plays a significantly positive role in improving regional ecoefficiency. As an important informal institution, regional trustworthiness is helpful to shape a good business environment for firms to facilitate productive cooperation and eco-innovation, thus contributing to the improvement of regional eco-efficiency. 3) The positive effect of social trust on improving regional eco-efficiency is more pronounced in regions with poor legal development. Empirical results indicate that in China's institution setting, the formal institution (legal development) and the informal institution (social trust) have a substitute governance impact on promoting economic sustainable development. 4) The mechanism tests further show that social trust can improve regional eco-efficiency through promoting regional green innovation and improving regional finance development. In the process of green development, regional green innovation and financial support undoubtedly play a critical role (Zhang et al., 2018; De Jesus et al., 2019). This paper find that regional trustworthiness has positive influence on promoting regional green innovation and developing regional finance, thus providing assistance for the improvement of region eco-efficiency. Our findings are robust to alternative measures of social trust and remain valid after using two-stage least squares estimation to control for the endogeneity between social trust and regional eco-efficiency.

\section{Policy Implications}

Our study also provides several important implications. First, the government needs to lay enough stress on sustainable economic development, and implement relevant policies to promote regional ecological efficiency. In the current stage, China is undergoing a key transition from high-speed to high-quality economic growth. However, the environmental issues arising from the course of high-speed development have become grave constraints. Therefore, the government has incorporated the construction of ecological civilization into the strategic layout of national development. Governments at all levels need to proactively introduce and implement regional green development-related policies, such as tax deductions and government subsidies, so as to comprehensively stimulate regional economic transition, improve regional eco-efficiency, and promote green, circular and low-carbon development.

Second, it is important to give full play to the complementary role of informal system in economical green development. Employing the data of China's 30 provinces from 2001 to 2016, this paper empirically reveals the important influence of social trust on economic development in emerging markets. In the transition economy with a relatively immature formal system (Allen et al., 2005), social trust can better play the role of alternative mechanism in achieving a sustainable economic development and improving regional ecological efficiency. When governing regional economy and society, governments at all levels can make use of formal systems, such as laws and policies, to supervise and regulate the potential environmental pollution behavior of enterprises within their jurisdiction. Moreover, it is also necessary to make full use of the positive effect of informal institutions on environmental governance. With an organic combination of formal and informal 
mechanisms, the government can mobilize enterprises within its jurisdiction to protect the environment in a more comprehensive way, thus encourage them contribute more in improving regional ecological efficiency and building a beautiful China. Therefore, the government should attach importance to creating a cultural soil that is conducive to the cultivation of regional social trust, and then let social trust exert positive influence on green development of regional economy.

Third, we need to stimulate regional ecological innovation to promote economic transformation and upgrading. In the transformation of regional economy, the government needs to stimulate the vitality of regional green innovation and promote the deep integration of the real economy with the Internet, big data, artificial intelligence, thus providing impetus and support for the improvement of regional eco-efficiency. In addition, it is important to develop regional finance to ensure financial support for the improvement of regional eco-efficiency. The government should speed up the reform of fiscal and taxation systems and financing mechanisms to further optimize the efficiency of resource allocation. Governments at all levels need to further improve the green credit management system and increase financial support for a green, circular and low-carbon economy to facilitate economic restructuring and industrial upgrading. By vigorously developing green finance, we can promote the financial sector to better serve the real economy, thus improving regional green development performance.

\section{Limitation and Future Directions}

There are some limitations in this paper. First, social trust is only a part of the informal institutions. In the future, we can explore the impact of other informal institutions, such as hometown connections, Confucianism and religious belief, on the sustainable development of Chin's economy. Second, the

\section{REFERENCES}

Allen, F., Qian, J., and Qian, M. (2005). Law, Finance, and Economic Growth in China. J. Financial Econ. 77 (1), 57-116. doi:10.1016/j.jfineco.2004.06.010

Almeida, H., and Campello, M. (2007). Financial Constraints, Asset Tangibility, and Corporate Investment. Rev. Financ. Stud. 20 (5), 1429-1460. doi:10.1093/ $\mathrm{rfs} / \mathrm{hhm} 019$

Ang, J. S., Cheng, Y., and Wu, C. (2015). Trust, Investment, and Business Contracting. J. Financ. Quant. Anal. 50 (3), 569-595. doi:10.1017/ S002210901500006X

Baker, S. R., Bloom, N., and Davis, S. J. (2016). Measuring Economic Policy

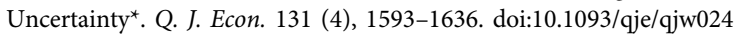

Baron, R. M., and Kenny, D. A. (1986). The Moderator-Mediator Variable Distinction in Social Psychological Research: Conceptual, Strategic, and Statistical Considerations. J. Personal. Soc. Psychol. 51 (6), 1173-1182. doi:10.1037//0022-3514.51.6.1173

Baxamusa, M., and Jalal, A. (2016). CEO's Religious Affiliation and Managerial Conservatism. Financial Manage. 45 (1), 67-104. doi:10.1111/fima.12080

Bing, W., Yanrui, W., and Pengfei, Y. (2010). Environmental Efficiency and Environmental Total Factor Productivity Growth in China's Regional Economies. Econ. Res. J. 5, 95-109. Available at: http://en.cnki.com.cn/ Article_en/CJFDTOTAL-JJYJ201005008.htm

Chen, F., Zhao, T., and Wang, J. (2019a). The Evaluation of Energy-Environmental Efficiency of China's Industrial Sector: Based on Super-SBM Model. Clean. Techn Environ. Pol. 21 (7), 1397-1414. doi:10.1007/s10098-019-01713-0 ecological efficiency we assessed is mainly focused on the provincial level in China, and cannot go deep into the citylevel and micro-enterprise level. In the future, we need to continue to dig deeper into relevant data to explore the green development efficiency with more microscopic data.

\section{DATA AVAILABILITY STATEMENT}

The raw data supporting the conclusion of this article will be made available by the authors, without undue reservation.

\section{AUTHOR CONTRIBUTIONS}

YY: Conceptualization, Data curation, Formal analysis, Methodology, Writing-original draft; JC: Data curation, Formal analysis, Methodology, Writing-original draft; YW: Investigation; YL: Writing-review and editing.

\section{FUNDING}

This research was funded by the Graduate Scientific Research and Innovation Foundation of Chongqing (No. CYB20049); Major Program of National Social Science Foundation of China (No. 19ZDA082); National Natural Science Foundation of China (No. 71972017 and 71802169); Philosophy and Social Sciences Foundation of Ministry of Education of China (No. 18JHQ079); Key Project of Philosophy and Social Sciences Research of Chongqing Municipal Education Commission (19SKZDZX11); Fundamental Research Funds for the Central Universities (No. 2019 CDJSK02XK 11 and 2019CDJSK02PT21).

Chen, L., Jin, Z., Ma, Y., and Xu, H. (2019b). Confucianism, Openness to the West, and Corporate Investment Efficiency. Eur. Financial Manage. 25 (3), 554-590. doi:10.1111/eufm.12173

Chen, S., and Golley, J. (2014). 'Green' Productivity Growth in China's Industrial Economy. Energ. Econ. 44, 89-98. doi:10.1016/j.eneco.2014.04.002

Cline, B. N., and Williamson, C. R. (2016). Trust and the Regulation of Corporate Self-Dealing. J. Corporate Finance 41, 572-590. doi:10.1016/ j.jcorpfin.2016.07.016

Coleman, J. S. (1990). Foundations of Social Theory. Cambridge, MA: Harvard University Press. doi:10.1093/sf/69.2.625

Cull, R., Li, W., Sun, B., and Xu, L. C. (2015). Government Connections and Financial Constraints: Evidence from a Large Representative Sample of Chinese Firms. J. Corporate Finance 32, 271-294. doi:10.1596/1813-9450-635210.1016/ j.jcorpfin.2014.10.012

De Jesus, A., Antunes, P., Santos, R., and Mendonça, S. (2019). Eco-innovation Pathways to a Circular Economy: Envisioning Priorities through a Delphi Approach. J. Clean. Prod. 228, 1494-1513. doi:10.1016/j.jclepro.2019.04.049

Du, X. (2015). Does Confucianism Reduce Minority Shareholder Expropriation? Evidence from China. J. Bus. Ethics 132 (4), 661-716. doi:10.1007/s10551-0142325-2

Färe, R., Grosskopf, S., Norris, M., and Zhang, Z. (1994). Productivity Growth, Technical Progress, and Efficiency Change in Industrialized Countries. Am. Econ. Rev. 84 (1), 66-83. doi:10.2307/2117971

Feng, C., and Wang, M. (2018). Analysis of Energy Efficiency in China's Transportation Sector. Renew. Sustain. Energ. Rev. 94, 565-575. doi:10.1016/ j.rser.2018.06.037 
Feng, C., Wang, M., Liu, G.-C., and Huang, J.-B. (2017). Green Development Performance and its Influencing Factors: A Global Perspective. J. Clean. Prod. 144, 323-333. doi:10.1016/j.jclepro.2017.01.005

Feng, Z., and Chen, W. (2018). Environmental Regulation, green Innovation, and Industrial green Development: An Empirical Analysis Based on the Spatial Durbin Model. Sustainability 10 (1), 223. doi:10.3390/su10010223

$\mathrm{Fu}$, J., Hu, J., and Cao, X. (2018). Different Sources of FDI, Environmental Regulation and Green Total Factor Productivity. J. Int. Trade 2018, 134-148. doi:10.13510/j.cnki.jit.2018.07.011

Garrett, J., Hoitash, R., and Prawitt, D. F. (2014). Trust and Financial Reporting Quality. J. Account. Res. 52 (5), 1087-1125. doi:10.2139/ssrn.213795710.1111/ 1475-679x.12063

Guiso, L., Sapienza, P., and Zingales, L. (2008). Social Capital as Good Culture. SSRN J. 6 (2-3), 295-320. doi:10.2139/ssrn.1077672

Guiso, L., Sapienza, P., and Zingales, L. (2004). The Role of Social Capital in Financial Development. Am. Econ. Rev. 94 (3), 526-556. doi:10.2307/ 359294110.1257/0002828041464498

Guo, Y., Tong, L., and Mei, L. (2020). The Effect of Industrial Agglomeration on green Development Efficiency in Northeast China since the Revitalization. J. Clean. Prod. 258, 120584. doi:10.1016/j.jclepro.2020.120584

Hou, J., An, Y., Song, H., and Chen, J. (2019a). The Impact of Haze Pollution on Regional Eco-Economic Treatment Efficiency in China: An Environmental Regulation Perspective. Ijerph 16 (21), 4059. doi:10.3390/ijerph16214059

Hou, X., Liu, J., Zhang, D., Zhao, M., and Xia, C. (2019b). Impact of Urbanization on the Eco-Efficiency of Cultivated Land Utilization: A Case Study on the Yangtze River Economic Belt, China. J. Clean. Prod. 238, 117916. doi:10.1016/ j.jclepro.2019.117916

Hsu, P.-H., Tian, X., and Xu, Y. (2014). Financial Development and Innovation: Cross-Country Evidence. J. Financial Econ. 112 (1), 116-135. doi:10.1016/ j.jfineco.2013.12.002

Huang, J., Yang, X., Cheng, G., and Wang, S. (2014). A Comprehensive EcoEfficiency Model and Dynamics of Regional Eco-Efficiency in China. J. Clean. Prod. 67, 228-238. doi:10.1016/j.jclepro.2013.12.003

Jha, A. (2017). Financial Reports and Social Capital. J. Bus. Ethics 155 (2), 567-596. doi:10.1007/s10551-017-3495-5

Ke, R., and Zhang, W. (2002). Trust in China: A Cross-Regional Analysis. Econ. Res. J. 10 (10), 1-22. doi:10.2139/ssrn.577781

Kong, D., Pan, Y., Tian, G. G., and Zhang, P. (2020). CEOs' hometown Connections and Access to Trade Credit: Evidence from China. J. Corporate Finance 62, 101574. doi:10.1016/j.jcorpfin.2020.101574

Kung, J. K.-S., and Ma, C. (2014). Can Cultural Norms Reduce Conflicts? Confucianism and Peasant Rebellions in Qing China. J. Develop. Econ. 111, 132-149. doi:10.1016/j.jdeveco.2014.08.006

La Porta, R., Lopez-de-Silanes, F., Shleifer, A., and Vishny, R. W. (1998). Law and Finance. J. Polit. Economy 106 (6), 1113-1155. doi:10.1086/250042

Li, X., Wang, S. S., and Wang, X. (2017). Trust and Stock price Crash Risk: Evidence from China. J. Banking Finance 76, 74-91. doi:10.1016/j.jbankfin.2016.12.003

Lin, B., and Xu, M. (2018). Regional Differences on CO2 Emission Efficiency in Metallurgical Industry of China. Energy Policy 120, 302-311. doi:10.1016/ j.enpol.2018.05.050

Lu, C.-H., and Pang, Y. (2017). An Anatomy of China's Eco-Efficiency Gains: The Role of FDI. SSRN J. 24 (1-2), 106-126. doi:10.2139/ssrn.234861710.1080/ 16081625.2015.1062244

North, D. C. (1990). Institutions, Institutional Change and Economic Performance. Cambridge: Cambridge University Press. doi:10.1017/CBO9780511808678

Pastor, J. T., and Lovell, C. A. K. (2005). A Global Malmquist Productivity index. Econ. Lett. 88 (2), 266-271. doi:10.1016/j.econlet.2005.02.013

Porta, R. L., Lopez-de-Silane, F., Shleifer, A., and Vishny, R. (1997). Trust in Large Organizations. Am. Econ. Rev. 87 (2), 333. doi:10.3386/w5864

Putnam, R. D., Leonardi, R., and Nanetti, R. Y. (1994). Making Democracy Work: Civic Traditions in Modern Italy. Princeton: Princeton university press. doi:10.2307/262079310.1515/9781400820740

Shuai, S., and Fan, Z. (2020). Modeling the Role of Environmental Regulations in Regional green Economy Efficiency of China: Empirical Evidence from Super Efficiency DEA-Tobit Model. J. Environ. Manage. 261, 110227. doi:10.1016/ j.jenvman.2020.110227
Solow, R. M. (1957). Technical Change and the Aggregate Production Function. Rev. Econ. Stat. 39 (3), 312-320. doi:10.2307/1926047

The World Bank (2020). Doing Business 2020: Comparing Business Regulation in 190 Economies. Available at: www.doingbusiness.org/en/doingbusiness.

Wang, A., and Lin, B. (2018). Dynamic Change in Energy and CO2 Performance of China's Commercial Sector: A Regional Comparative Study. Energy Policy 119, 113-122. doi:10.1016/j.enpol.2018.04.036

Wang, H., and Yang, J. (2019). Total-factor Industrial Eco-Efficiency and its Influencing Factors in China: A Spatial Panel Data Approach. J. Clean. Prod. 227, 263-271. doi:10.1016/j.jclepro.2019.04.119

Wang, Q., Chiu, Y.-H., and Chiu, C.-R. (2017). Non-radial Metafrontier Approach to Identify Carbon Emission Performance and Intensity. Renew. Sustain. Energ. Rev. 69, 664-672. doi:10.1016/j.rser.2016.11.199

Wang, R. (2018). The Effect of FDI on Ecological Efficiency in China's Regional Eco-Efficiency under the Third-Country Effects. Ekoloji 27 (106), 383-393. Available at: http://www.ekolojidergisi.com/article/ the-effect-of-fdi-on-ecological-efficiency-in-chinas-regional-eco-efficiencyunder-the-third-5373

Williamson, O. E. (2000). The New Institutional Economics: Taking Stock, Looking Ahead. J. Econ. Lit. 38 (3), 595-613. doi:10.1257/jel.38.3.595

Wu, W., Firth, M., and Rui, O. M. (2014). Trust and the Provision of Trade Credit. J. Banking Finance 39, 146-159. doi:10.1016/j.jbankfin.2013.11.019

Xu, X., Duan, L., and Yan, Y. (2019). The Influence of Confucianism on Corporate Environmental Investment: Evidence from Chinese Private Firms. Sustainability 11 (21), 5941. doi:10.3390/su11215941

Xu, X., and Yan, Y. (2019). Effect of Political Connection on Corporate Environmental Investment: Evidence from Chinese Private Firms. Appl. Econ. Lett. 27, 1515-1521. doi:10.1080/13504851.2019.1693692

Yan, Y., and Xu, X. (2020). Does Entrepreneur Invest More in Environmental Protection when Joining the Communist Party? Evidence from Chinese Private Firms. Emerging Markets Finance and Trade 56, 1-22. doi:10.1080/ 1540496X.2020.1848814

Yan, Y., Xu, X., and Lai, J. (2021). Does Confucian Culture Influence Corporate R\&D Investment? Evidence from Chinese Private Firms. Finance Res. Lett. 40, 101719. doi:10.1016/j.frl.2020.101719

Yang, J., Cheng, J., and Huang, S. (2020). CO2 Emissions Performance and Reduction Potential in China's Manufacturing Industry: A Multi-Hierarchy Meta-Frontier Approach. J. Clean. Prod. 255, 120226. doi:10.1016/ j.jclepro.2020.120226

Yu, J., Zhou, K., and Yang, S. (2019). Regional Heterogeneity of China's Energy Efficiency in "new normal": A Meta-Frontier Super-SBM Analysis. Energy Policy 134, 110941. doi:10.1016/j.enpol.2019.110941

Zhang, J., Chang, Y., Zhang, L., and Li, D. (2018). Do technological Innovations Promote Urban green Development?-A Spatial Econometric Analysis of 105 Cities in China. J. Clean. Prod. 182, 395-403. doi:10.1016/ j.jclepro.2018.02.067

Zhou, Y., Kong, Y., Wang, H., and Luo, F. (2020). The Impact of Population Urbanization Lag on Eco-Efficiency: A Panel Quantile Approach. J. Clean. Prod. 244, 118664. doi:10.1016/j.jclepro.2019.118664

Conflict of Interest: The authors declare that the research was conducted in the absence of any commercial or financial relationships that could be construed as a potential conflict of interest.

Publisher's Note: All claims expressed in this article are solely those of the authors and do not necessarily represent those of their affiliated organizations, or those of the publisher, the editors and the reviewers. Any product that may be evaluated in this article, or claim that may be made by its manufacturer, is not guaranteed or endorsed by the publisher.

Copyright (c) 2021 Yan, Cheng, Wang and Li. This is an open-access article distributed under the terms of the Creative Commons Attribution License (CC $B Y$ ). The use, distribution or reproduction in other forums is permitted, provided the original author(s) and the copyright owner(s) are credited and that the original publication in this journal is cited, in accordance with accepted academic practice. No use, distribution or reproduction is permitted which does not comply with these terms. 